\title{
The Development and Implementation of a Model for Teaching Astronomy to Deaf Students
}

\author{
Mualla Bolat \\ Correspondence: Mualla Bolat, Science Education Program, Faculty of Education, Ondokuz Mayss University, Samsun, \\ 55200, Turkey
}

Received: January 18, 2016 Accepted: March 28, 2016 Online Published: March 30, 2016

doi:10.11114/jets.v4i7.1506

URL: http://dx.doi.org/10.11114/jets.v4i7.1506

\begin{abstract}
The purpose of this study is to develop and assess a model aimed at teaching astronomy to deaf students. Thus, a 7 day-long project of indoor and outdoor activities was developed. Since the purpose of our study was to teach astronomy to deaf students, our sample was determined by using purposeful sampling technique. The sample of this study includes 30 deaf students studying in the city of Samsun in the Black Sea region of Turkey. A teaching model for deaf students, which was considered to be a deficiency in literature, was developed in the study. The pre-implementation preparation stage of the model consists of 7 steps. In addition, the activities in the model were included in the study so that other researchers can use these activities. This study was designed as a single group (no control) post-test experimental research design. The data of the study were collected from the interviews with students during the experimental studies and post-tests which were conducted 20 days after the studies ended. At the end of the study, it was seen that a great majority of the students learned more than 10 words and were able to order the astronomy related celestial bodies based on their sizes. In addition, it was concluded that they began to develop scientific ideas about the seasons, a subject they had no knowledge about before the study, and they were able to explain the effects of Earth's axial tilt on daily life correctly. In line with these results, it was suggested that in order to teach a subject to deaf students, first of all sign language about that subject should be developed and conceptual learning and teaching sign language should be simultaneous.
\end{abstract}

Keywords: deaf students, astronomy education, science education, teaching model

\section{Introduction}

Deafness is defined as the condition of hearing accuracy not doing its duty in a person's development, adaptation and especially communication while a deaf person is defined as a person who requires special education due to hearing impairment (Özsoy, Özyürek \& Eripek, 1997). According to another researcher, a deaf person is someone who cannot hear sounds enough for communication and information (GrØnlie, 1995; Moores, 1987). Deaf students learn the knowledge and concepts they are expected to learn at school incompletely. According to GrØnlie (1995) and Moores (1987), the following are the results of insufficient learning in deaf students;

- The parents of deaf students do not know the sign language (90\%).

- Since deaf students cannot hear the natural spoken language, they cannot learn it.

- Since they cannot learn the spoken language, their writing skills are weak.

- In order to overcome this problem, a lot of time has been spent for students at schools for deaf students and other school subjects have been neglected. The effort was not as effective as expected.

- Since the policies of these schools and the ability to reach written knowledge were poor, deaf students got low levels of education and they were informed in low levels.

As in individuals with normal development, deaf individuals also have specific and different ways of learning. Learning styles should be determined for deaf students to get a better education. If the students' dominant learning styles are determined, it can be easier to understand how individuals learn and what type of learning design should be implemented (Snyder, Rebscher, Cao, Leake, Kelly, 1990). Deaf students use visual elements more in order to gain knowledge and communicate. They use sign language to communicate with each other and other people (Roald \& Mikalsen, 2000). Since they develop their sign language visually/spatially, there occur differences in sign language in 
terms of country and geography (Baron, 1981; Martin, 1985; Mertens, 1991; Moores 1987).

\subsection{Studies Aimed at Teaching Science and Astronomy to the Deaf Students}

There are limited numbers of studies conducted on science teaching with deaf students. Wang (2011) stated that studies conducted with deaf students were poor and there were only 12 studies on science teaching with deaf students in the last 40 years. Similarly, Molander, Pedersen \& Norell (2001) emphasized in his study that studies conducted with deaf students mostly focused on language acquisitions and few studies were on science teaching. Examples of these few numbers of studies are studies by Barman \& Stockton (2002), Borrón (1978), Boyd \& George, (1973), Diebold \& Waldron (1988), Egelston-Dodd \& Ting (2007), Elefant (1980), Lang \& Albertini (2001), Pandian (2006), Roald \& Mikalsel (2000, 2001), Vosganoff, Paatsch, \& Toe (2011), Wang (2011), Zamfirov, Saeva \& Popov (2007). Some of these studies conducted on the astronomy education to the deaf students (Egelston-Dodd \& Ting, 2007; Pandian, 2006; Roald \& Mikalsel, 2001; Zamfirov, Saeva \& Popov, 2007).

Wang (2011) conducted a three stage research with deaf students. First, he presented a point of view on the regulations of science based education which included the socio-historical forces behind the subject of "movement". Then, the author examined and defined the experimental studies about teaching science to deaf students or students with hearing difficulty from 1970s to today and compared web based instructions. After discussing the difficulty of using science texts with deaf students or students with hearing difficulty, the author presented a contextual framework I"n which web based knowledge and performance literacy were integrated. The study pointed out that this integration should be activated in order to reach the general education curriculum in deaf students or students with hearing difficulty.

According to Lang \& Steely (2003), web based science education generally includes activities which increase the learning levels of deaf students. At the same time, the author stated that while developing a web based teaching material, there were points to be careful about the use of this material by deaf students. Especially the teachers of deaf students should be aware that visual supplements about the reading skills, motivation of students and scientific content.

In their study, Roald \& Mikalsen (2001) examined the conceptual models of 7, 9, 11 and 17 years old Norwegian children and 9 years old Norwegian children who were not deaf. At the end of the study, it was found that the mental models of students were mostly around "native" and "synthetic" model. As stated in another study, French deaf society has a direct access to Paris-Meudon observatory and telescopes. This way, new sign language words are developed in the area of astronomy and brought to French Sign Language. In the light of scientific knowledge obtained from this study, "The Hands in the Stars" dictionary was formed (Proust, Abbou \& Chab, 2009).

Egelston-Dodd \& Ting (2007) developed a web based astronomy lesson for freshmen deaf students at Rochester Technology Institute (Rochester, NY). They introduced American Sign Language (ASL) which is used within the context of this lesson and which includes technical words and concepts. Deaf students showed success in astronomy with very little misconceptions. In addition, it was concluded that after students used ASL vocabulary videos they had higher ASL learning skills. In a similar study by Zamfirov, Saeva \& Popov (2007), a new strategy was developed on deaf $7^{\text {th }}$ graders (13 year old students) and $8^{\text {th }}$ graders (14 year old students) to be used in the teaching of physics and astronomy. This strategy provides an effective education not only for deaf students, but also for students studying at private schools. A "Multimedia CD" was prepared which included a great number of physics and astronomy terms with textual knowledge and various pictures. The terms were explained in Bulgarian, Bulgarian Sign Language and English.

When the studies mentioned above are examined, no studies were found to form a suitable model in teaching astronomy subjects to deaf students. Thus, a model (project) was developed to realize the lacks of deaf students on science education (especially astronomy education) and to contribute to improvement in this area.

\subsection{The Purpose of Research}

The purpose of this study was to prepare a model for the teaching of astronomy to deaf students. Accordingly, the Project "No obstacle for me to learn astronomy" was prepared and supported by The Scientific and Technological Research Council of Turkey (STRCT)

Thus, the research tries to answer the following questions.

"What are the effects of "No obstacles for me to learn astronomy" project on the astronomy achievement of deaf students?

Starting from this research problem, answers were sought for the following sub-problems:

- What are the new concepts learned by deaf students in the field of astronomy?

- What are the alternative concepts of deaf students in the field of astronomy?

- What is the practicality of the project? 


\section{Method}

This study was designed as a single group (no control) post-test research. In this design, the researcher conducts the implementation and performs the measurement. In this design, independent variable is used on the single group formed to examine to what extent the effect creates on the dependent variable. This model can be used if the researchers have knowledge about the pre-implementation knowledge levels of the students (Tanriöğen, 2009). In the meetings with the teachers working in the school where the study was conducted before the project was started, the teachers stated that the students did not have knowledge about the subjects and concepts the projects aimed to teach. Thus, no pre-test was implemented in the study. In addition, since the study was conducted with the students who participated in the astronomy education project, there is no control group.

\subsection{Sample}

The sample of the study was determined by using purposeful sampling technique, which is one of the non-random sampling methods. In this sampling method, the universe is grouped in clusters in line with the purpose of the research. The cluster which is thought to be the most suitable for the research is chosen as the sample (Büyüköztürk, 2010; Tanrı̈ğgen, 2009). Thus, since the purpose of our study was to teach astronomy to deaf students, our sample was chosen accordingly. The sample of this study consists of deaf students who participated in the "No obstacles for me to learn astronomy" project which was supported by STRCT and which was organized in a city in the Black Sea region of Turkey. Table 1 presents the demographic characteristics of the participants.

Table 1. Demographic characteristics of the participants

\begin{tabular}{cccc}
\hline & \multicolumn{3}{c}{ Gender } \\
\hline Age & Female & Male & Total \\
\hline $11-14$ & 6 & 4 & 10 \\
$14-18$ & 9 & 11 & 20 \\
\hline
\end{tabular}

\subsection{Data Collection and Analysis}

The data of the study were collected from interviews with the students during the experimental studies and the post-test results which were conducted 20 days after the studies finished. In post-test implementation, there were drawing questions rather than explanatory questions. The questions asked to the students are below:

- Which words did you learn in sign language in "No obstacles for me to learn astronomy" project?

- Draw the Solar eclipse.

- Draw the Lunar eclipse.

- What are the consequences of the axial tilt of the Earth?

- Order the following celestial bodies from the biggest to the smallest. Space, Earth, Galaxy, Star

- Order the following celestial bodies from the biggest to the smallest. Sun, Earth, Jupiter, Moon

- $\quad$ In the figure below, where does the Sun rise and set? Mark.

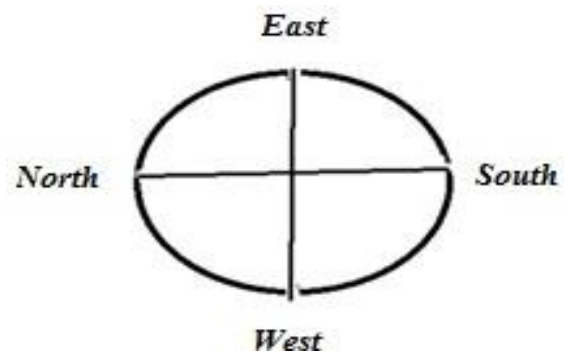

In the data analysis section, descriptive statistics were calculated for the students' answers to the questions. In addition, interviews with the students were analyzed descriptively. In order to ease this analyses and to be able to quote directly, the students who participated in the study were coded by numbering as $S_{1}, S_{2}, \ldots, S_{30}$ from 1 to 30 . Finally, some examples of students' answers to drawings and explanatory questions were shown in the results section.

\subsection{Information about the Project and Implementation}

"No obstacles for me to learn astronomy" education project is a project which was found to be worth being supported by STRCT. Different places were used in the implementation of the project which lasted for 7 days in total. In the first 
four days, the project was implemented in Ondokuz Mayis University Astronomy Center and in the last three days, the implementations were conducted exterritorialy in Kizılırmak Delta.

\subsubsection{Project Preparation Stage}

1. Which concepts do the students know about astronomy in sign language and which concepts should be taught?

In the first stage of the study, it was found which words deaf students knew about astronomy in sign language. To do this, interviews were made with the deaf students through their teachers. In general, it was found that the words that the students stated they knew were only words of seasons, stars and the Sun. It was decided on which new concepts to derive in order to be able to implement the model to be prepared in astronomy education. These concepts were astronomy, telescope, planet, solar system, comet, galaxy, Milky Way galaxy, universe, scale, solar eclipse, lunar eclipse and axial tilt.

2. How will the concepts be added in sign language?

In the second part of this model, preparations were made to make the students learn these concepts. An order was determined to teach these concepts to students. This order was telescope, astronomy, scale, planet, solar system, comet, galaxy, Milky Way galaxy, universe, solar eclipse, lunar eclipse and axial tilt. The concepts which were determined by using visuals, videos, planetarium and hands-on astronomy models were introduced to students. Thus, starting from the students' own perceptions, words were formed in sign language about these concepts.

3. Which activities will be performed to teach the new concepts?

Activities for the teaching of new concepts were grouped under two themes. These themes are basic astronomy theme and seasons. Table 2 presents the activities in these themes.

Table 2. The activities in these themes

\begin{tabular}{l|ll}
\hline \multicolumn{1}{c|}{ Basic Astronomy Theme } & \multicolumn{1}{c}{ Seasons Theme } \\
\hline$-\quad$ I'm exploring the space & $-\quad \begin{array}{l}\text { Where does the Sun rise from? Where does it } \\
\text { set from? }\end{array}$ \\
$-\quad$ How big how far? & $-\quad \begin{array}{l}\text { Let's observe the moves of the Sun in the sky } \\
-\quad \text { Let's raise our heads up }\end{array}$ & $-\quad \begin{array}{l}\text { I'm measuring the length of the ruler's } \\
\text { shadow }\end{array}$ \\
$-\quad$ I'm having fun in the planetarium & $-\quad$ Does the heat change? \\
$-\quad$ I'm scaling the solar system & $-\quad$ Does the time of day change? \\
$-\quad$ I'm modeling the solar eclipse and the lunar & $-\quad$ Let's calculate the time of day \\
& $-\quad$ Let's evaluate the data \\
& $-\quad \begin{array}{l}\text { let's model the movements of the Sun in the } \\
\text { sky }\end{array}$ \\
& $-\quad$ Why do these happen? \\
\hline
\end{tabular}

4. Which methods and media will be used for the teaching of new concepts?

The decisions about which methods and media to use while teaching the new concepts to deaf students were made together with expert trainers in the field. Table 3 shows the methods and media to be used.

Table 3. Methods and media used in the project

\begin{tabular}{lll}
\hline Subject & Method & Environment \\
\hline Distance and size & Experiment, video, modeling & Indoor and outdoor \\
Lunar eclipse & Experiment, video, modeling & Indoor \\
Solar eclipse & Experiment, video, modeling & Indoor \\
What is in the solar system & Video, modeling & Indoor \\
Seasons & Experiment, modeling & Outdoor \\
\hline
\end{tabular}

5. How much time is required for these activities?

A total of 7 days, 4 days to develop the concepts in "basic astronomy theme" and 3 days in "seasons theme" were determined as the time required for all the activities. Table 4 shows the dates and names of activities for the theme of seasons. 
Table 4. Activities and dates of the theme of seasons

\begin{tabular}{|c|c|c|c|}
\hline \multirow[b]{2}{*}{ Activities } & \multicolumn{3}{|c|}{ Dates of activities } \\
\hline & $\begin{array}{c}21 \\
\text { June }\end{array}$ & $\begin{array}{c}23 \\
\text { September } \\
\end{array}$ & 21 December \\
\hline $\begin{array}{l}\text { Where does the Sun rise from? Where does it set } \\
\text { from? }\end{array}$ & $\checkmark$ & $\checkmark$ & $\checkmark$ \\
\hline Let's observe the moves of the Sun in the sky & $\checkmark$ & $\checkmark$ & $\checkmark$ \\
\hline I'm measuring the length of the ruler's shadow & $\checkmark$ & $\checkmark$ & $\checkmark$ \\
\hline Does the heat change? & $\checkmark$ & $\checkmark$ & $\checkmark$ \\
\hline Does the time of day change? & $\checkmark$ & $\checkmark$ & $\checkmark$ \\
\hline Let's calculate the time of day & $\checkmark$ & $\checkmark$ & $\checkmark$ \\
\hline let's evaluate the data & & & $\checkmark$ \\
\hline Let's model the movements of the Sun in the sky & & & $\checkmark$ \\
\hline Why do these happen? & & & $\checkmark$ \\
\hline
\end{tabular}

6. Which cognitive process skills will be used and taught?

Cognitive process skills which are taught to be developed in students through these activities were determined. Table 5 gives which cognitive process skills will be developed about which subjects.

Table 5. Cognitive process skills planned to be added to subjects

\begin{tabular}{ll}
\hline Subject & Cognitive process skills \\
\hline Distance and size & $\begin{array}{l}\text { observing, predicting, communicating, classifying, measuring, collecting } \\
\text { recording, and interpreting data, experimentation, making and using models } \\
\text { observing, predicting, communicating, classifying, experimentation, making } \\
\text { and using models } \\
\text { Lunar eclipse }\end{array}$ \\
$\begin{array}{l}\text { observing, predicting, communicating, classifying, experimentation, making } \\
\text { and using models } \\
\text { observing, communicating, experimentation, classifying, comparing, using } \\
\text { models } \\
\text { observing, predicting, communicating, classifying, measuring, collecting } \\
\text { recording, and interpreting data, experimentation, making and using models, } \\
\text { inferring }\end{array}$ \\
\hline
\end{tabular}

7. How will the teachers working in the activities be chosen and what kind of training will they get?

The teachers to work in activities consist of four teachers chosen from the school of the deaf. The teachers were teachers of primary school, mathematics and geography. Before the project started, the teachers were given in-service training about the activities in the project.

\subsubsection{Experimental Stage of the Project (Implementation)}

Experimental activities of the project and the contents of these activities are shortly summarized below.

I'm exploring the space: Students were shown various visuals and posters of the universe. The names of the celestial bodies were written under the visuals. This activity was supported by computer animations. The purpose was to add astronomy, telescope, universe, galaxy, Milky Way galaxy to sing language at the end of the activity.

How big how far: Beginning from $10^{+23}$ meters, that is 10 million light years away, to $10^{-6}$ meters, that is inside the atom, a step by step visual journey was made by the project team. This journey was made thanks to video show. The aim of this journey from macro universe to micro universe was to make the students grasp the concepts of size and distance.

Let's raise our heads up: The sky was observed through telescope and some close celestial bodies were watched.

I'm having fun in the planetarium: A 3D journey was made to the solar system, stars, galaxies and galaxy groups in the planetarium.

What is in the solar system: The order and names of the planets were given from solar system posters, planets were scaled and made from play dough. The purpose of this study was to add concepts such as solar system, planets and comet to the sign language. The example photo of this activity is given in Figure 1. 


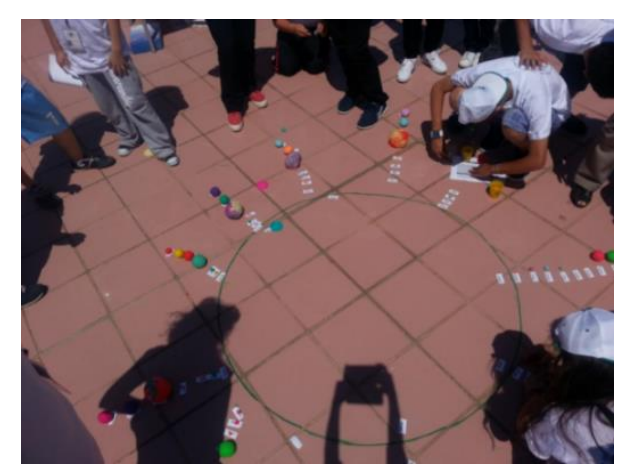

Figure 1. "What is in the solar system" activity

I'm scaling the solar system: The planets in the solar system were placed on a 10 meter black cardboard with the specified scale based on their distance to the Sun. The scale which was formed is both for size and distance. The colors of the Sun and the planets were in accordance with the original color. The purpose of this activity was to add the concept of "scale" to the sign language. The example photo of this activity is given in Figure 2.

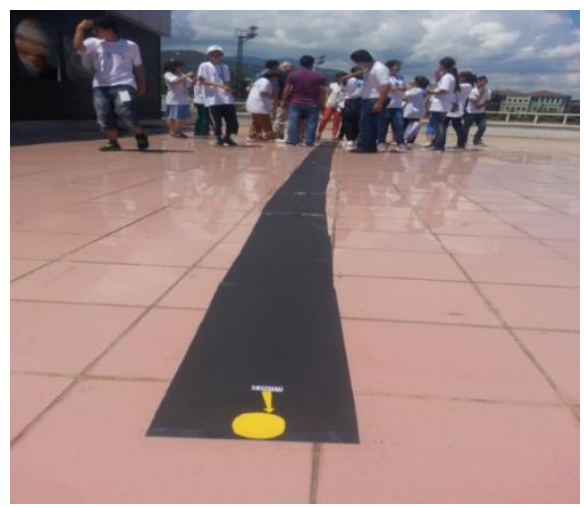

Figure 2. "I'm scaling the solar system" activity

I'm modeling the solar and lunar eclipse: Solar and lunar eclipse experiments were modeled by using the models of the Sun, the Earth and the Moon. In addition, solar and lunar eclipses were shown with computer animations. The purpose of this activity was to develop the concepts of solar and lunar eclipse in sign language.

Where does the Sun rise? Where does it set? In order to be able to observe the rise and set of the Sun from a fixed place on the activity days and to measure the change in angles, an orientation device was made. This device was made from three wooden sticks. The first stick was vertically put in the earth while the other two sticks were nailed vertically to each other and they were mounted on the stick which was on the earth. A compass was put on this mechanism and the directions of north, south, east and west were specified. Directions were written on the wood with a board marker. The mechanism showing the directions was fixed in a place during the activity. The rising and setting positions of the Sun in the morning and in the evening were observed with this mechanism. The place where the Sun rose in the morning was measured angularly with a compass. The same process was repeated at the sunset. Figure 3 shows the picture of the student who found and observed the sunset in the morning $\left(21^{\text {st }}\right.$ June) by using the compass mechanism.

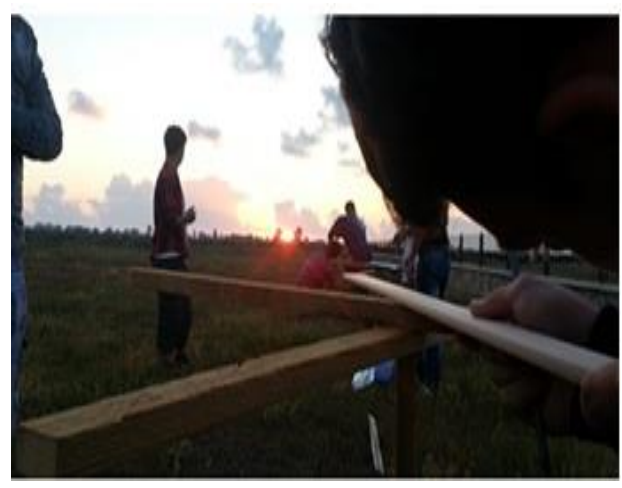

Figure 3. The student who is making observation 
Let's observe the movements of the Sun: On the specified dates, the photos of the Sun were taken every two hours between the rise and the setting of the Sun and the photos taken were downloaded in the students' computers.

I'm measuring the shadow length of the ruler: On activity days (the most upright position of the Sun for Samsun), midday was measured with the shadow length of $100 \mathrm{~cm}$ long ruler which was kept fixed.

Does the heat change? On activity days, the students measured and recorded the temperature at midday with thermometer.

Does the time of day change? Accompanied by their teachers, the students measured and recorded the time from the rise of the Sun to the set of the Sun.

Let's calculate the day time: Accompanied by their teachers, the students used the data they got on $21^{\text {st }} \mathrm{June}, 23^{\text {rd }}$ September and $21^{\text {st }}$ December in the activity of "Where does the Sun rise Where does it set?" also in this activity. They used a simple mathematical association between the angle change and the day time at the rise and set points of the Sun on each activity day, calculated the time of day and compared these with the times they measured.

Let's evaluate the data: The students recorded the data they obtained from activities on $21^{\text {st }}$ June, $23^{\text {rd }}$ September and $21^{\text {st }}$ December in Table 6 below. The students were asked to make conclusions by using these data.

Table 6. Observation recording table

\begin{tabular}{|c|c|c|c|}
\hline \multirow{2}{*}{\multicolumn{4}{|c|}{$\begin{array}{ll} & \mathbf{2 1}^{\text {st }} \text { June } \\
\text { Shadow Length }\end{array}$}} \\
\hline & & & \\
\hline Temperature & & & \\
\hline Day time (measured) & & & \\
\hline Day time (calculated) & & & \\
\hline Angle change & & & \\
\hline
\end{tabular}

Let's model the moves of the Sun in the sky: A model which showed the route of the Sun in the sky on activity days ( $21^{\text {st }}$ June, $23^{\text {rd }}$ September and $21^{\text {st }}$ December) was made. On this model, simple and easy to find materials were used such as copper wire, scissors, cartoon and glue.

- First of all, the students were grouped in three and the groups were given the materials to be used in the activities. These materials were round wires in circles, cartoon, scissors, and three different lengths of wire.

- Circle represents the ground plane. On this circle, the students were asked to stick the directions written on cartoon.

- They were asked to make little suns from the cartoons.

- The students were asked to place different lengths of wires on the rising and setting places of the Sun on $21^{\text {st }}$ June, $23^{\text {rd }}$ September and $21^{\text {st }}$ December at midday according to the tilt of the Sun.

\section{Findings}

The data obtained from the study were presented in two parts. The data the students got and the interviews with the students were given in part 1, while the data obtained from the post-tests with the students after the project were given in part 2.

\subsection{Findings of the Interview}

When the findings of the student interviews were given, direct quotations were made. The researcher who made the interview was described with the letter " $R$ ", while the students interviewed were described with the letter "S".

The findings of the interviews with students $S_{12}, S_{7}$ and $S_{20}$ on $21^{\text {st }}$ June, $23^{\text {rd }}$ September and $21^{\text {st }}$ December were given below. Interviews were made with each student on each date and the changes (if any) were examined.

$>$ The findings of the interview with student $\mathrm{S}_{12}$ on $20^{\text {th }}$ June are given below:

$\mathrm{R}$ : We'll observe the sunrise and sunset altogether tomorrow. From where do you think the Sun will rise tomorrow?

$\mathrm{S}_{12}:$ From east

$\mathrm{R}$ : Are you sure?

$\mathrm{S}_{12}$ :Yes.

R: How do know that?

$\mathrm{S}_{12}$ : It is always said like that. The Sun rises from the east and sets from the West.

$>$ The findings of the interview with student $\mathrm{S}_{7}$ on $21^{\text {st }}$ June are given below:

$\mathrm{R}$ : Today is the 21 st of June. What do you think about the length of day and night? 
$\mathrm{S}_{7}$ : The day is long.

R: Why?

$\mathrm{S}_{7}$ : The Sun stays in the sky for a long time.

$\mathrm{R}:$ Why?

$\mathrm{S}_{7}$ : No answer.

The findings of the interview with student $\mathrm{S}_{20}$ on $21^{\text {st }}$ June are given below:

$\mathrm{R}$ : Is today $21^{\text {st }}$ June?

$\mathrm{S}_{20}$ : Yes

$\mathrm{R}$ : What time is it?

$\mathrm{S}_{20}: 9: 38$

$\mathrm{R}:$ Where do you think the Sun will be in midday??

$\mathrm{S}_{20}$ : On top of our heads (shows the top of his head with his hand).

R: Do you think so?

$\mathrm{S}_{20}$ :Yes

$\mathrm{R}:$ Will we have a shadow at noon today?

$\mathrm{S}_{23}$ :No

$\mathrm{R}:$ What about two months later?

$\mathrm{S}_{23}:$ No

$\mathrm{R}:$ Why?

$\mathrm{S}_{23}$ : The Sun always passes on top of our heads (shows the top of his head with his hand).

The findings of the interview with student $\mathrm{S}_{12}$ on $22^{\text {nd }}$ September are given below:

$\mathrm{R}:$ Where did the Sun rise from on 21 st June?

$\mathrm{S}_{12}$ : From the left of East (marks the paper).

$\mathrm{R}$ : Tomorrow is 23rd September. Where do you think the Sun will rise from?

$\mathrm{S}_{12}$ : I don't know. We were surprised the last time.

The findings of the interview with student $S_{7}$ on $23^{\text {rd }}$ September are given below:

$\mathrm{R}$ : Where did the Sun rise today?

$\mathrm{S}_{7}$ : East (surprised).

$\mathrm{R}$ : Were you expecting this?

$\mathrm{S}_{7}:$ No.

The findings of the interview with student $S_{20}$ on $23^{\text {rd }}$ September are given below:

$\mathrm{R}$ : We measured temperature pm $21^{\text {st }}$ June. You remember, right?

$\mathrm{S}_{20}$ : (Nods).

$\mathrm{R}:$ How was the weather?

$\mathrm{S}_{20}$ : Warm.

R: Today?

$\mathrm{S}_{20}$ : (Signs with his hand. Wraps his clothing).

$\mathrm{R}:$ Cold, you mean, why?

$\mathrm{S}_{20}$ : There are clouds.

$\mathrm{R}$ : But there is also the Sun.

$\mathrm{S}_{20}$ : The Moon blocks.

The findings of the interview with student $\mathrm{S}_{12}$ on $20^{\text {th }}$ December are given below: 
$\mathrm{R}:$ Where had the Sun risen from in your previous experiences?

$\mathrm{S}_{12}$ : On the left of east the first time, then from the east.

$\mathrm{R}$ : Where do you think the Sun will rise from tomorrow?

$\mathrm{S}_{12}$ : It will change (Looks with his hand).

The findings of the interview with student $\mathrm{S}_{7}$ on $21^{\text {th }}$ December are given below:

$\mathrm{R}$ : The ruler is $100 \mathrm{~cm}$ long, what happens if we measure the length of shadow now?

$\mathrm{S}_{7}$ : More?

R: Why?

$\mathrm{S}_{7}$ : (Shows the Sun with his hand) More oblique.

$>$ The findings of the interview with student $S_{20}$ on $21^{\text {th }}$ December are given below:

$\mathrm{R}$ : Where had the Sun risen from in previous activities?

$\mathrm{S}_{20}$ : From the left of east the first time

$\mathrm{R}:$ Later?

$\mathrm{S}_{20}$ : East

R: What about today?

$\mathrm{S}_{20}$ : From the right of the east (signing to the left side by showing the east with hand).

$\mathrm{R}:$ Where did it set?

$\mathrm{S}_{20}$ : From the right of the east the first time, then from the west and today from the left of the east.

$\mathrm{R}$ : Left of the west (showing with sign).

$\mathrm{S}_{20}$ : The Sun set from southwest today.

$\mathrm{R}$ : What happened when the sunset places changed?

$\mathrm{S}_{20}$ : The days got shorter.

R: Else?

$\mathrm{S}_{20}$ : The Sun passed more oblique.

R: Else?

$\mathrm{S}_{20}$ : The length of shadow increased. The temperature fell.

$\mathrm{R}:$ Why do these happen?

$\mathrm{S}_{20}$ : No answer (with curios eyes).

Figures 4 and 5 show the drawings of a student who observed the rise and set of the Sun during the day on $21^{\text {st } J u n e . ~}$

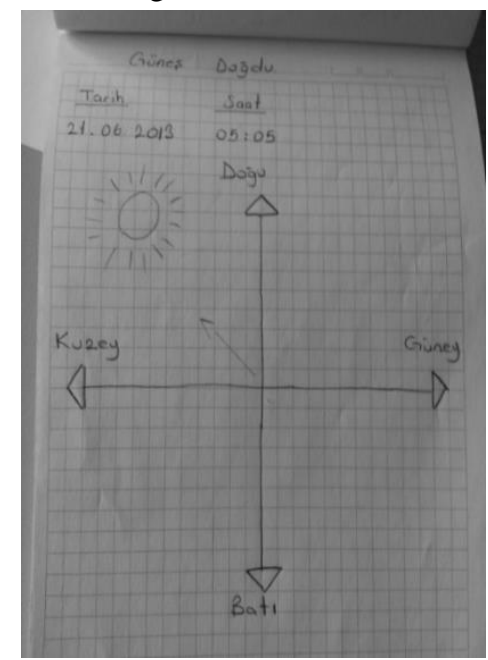

Figure 4. Sun rise

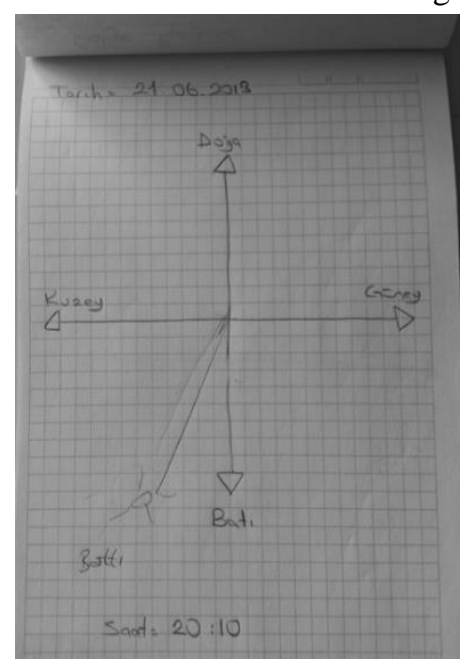

Figure 5. Sun set 


\subsection{Post-test Findings}

As a result of the answers to the question "Which new words in sign language did you learn about astronomy with the No obstacles for me to learn astronomy project", it was found that they learned between 9 to 13 new vocabularies. The numbers of students corresponding to the numbers of words learned were given in Table 7 .

Table 7. The number of new words students learned in sign language

\begin{tabular}{c|c|c|c|c|c}
\hline $\begin{array}{c}\text { The number of new words in sign } \\
\text { language }\end{array}$ & 13 & 12 & 11 & 10 & 9 \\
\hline The number of students & 4 & 5 & 4 & 2 & 5 \\
\hline
\end{tabular}

As can be seen from 7, the students had the opportunity to learn many new words and concepts in astronomy.

$>$ Another question asked to the students was "What are the consequences of Earth's axial tilt". In general, the students answered this question by drawing. Some of the examples of students' drawings are given in Figure 6 and Figure 7.

5.) Eksen eğikliğinin sonuçları nedir?

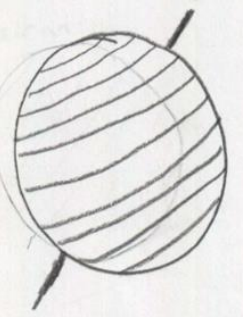

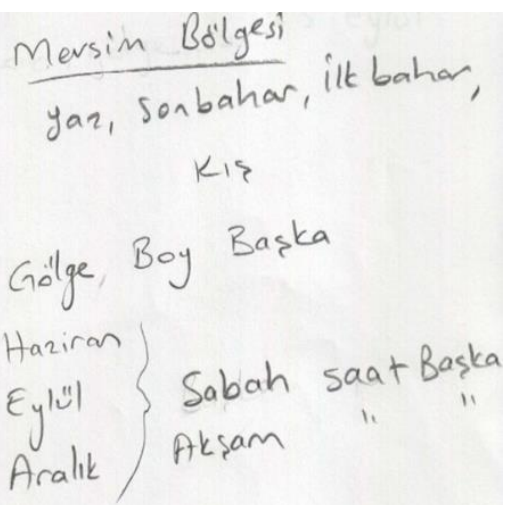

Figure 6. Sample answer for "What are the consequences of the Earth's tilt?" $\left(\mathrm{S}_{25}\right)$

Statement of student $S_{25}$ is striking. Because according to the student stated as a result of the Earth's axis tilt that:

- Changing seasons

- Changing the length of the shadow

- Changing point of Sun rise and set

5.) Eksen eğikliğinin sonuçları nedir?

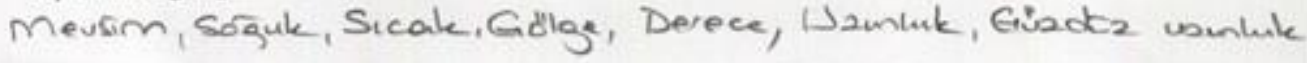

Figure 7. Sample answer for "What are the consequences of the Earth's tilt?" $\left(\mathrm{S}_{28}\right)$

Student $\mathrm{S}_{28}$ stated that a great number of parameters will change based on the Earth's axial tilt. These parameters are below.

- Seasons

- Length of shadow

- Temperature

- Time of day

$>$ In another question, the students were asked to write down some far away celestial bodies and to order these from the biggest to the smallest.

"Order the following celestial bodies from the biggest to the smallest"

- Space

- Earth

- Galaxy

- Star

The correct and incorrect answers of the students to this question are given in Table 8 in frequencies. 
Table 8 . The distribution of answers for students to far away celestial bodies

\begin{tabular}{lc}
\hline Answer & f \\
\hline Correct answer (Space-Galaxy-Star-Earth) & 16 \\
\hline Incorrect answer & 14 \\
\hline
\end{tabular}

The results in Table 8 show that for the first time in astronomy, for the first time, more than half of the deaf students answered this question correctly.

$>$ Similar to the precious question, some celestial bodies were written down and the students were asked to order these from the biggest to the smallest. However, this time better known bodies close to our Earth were written down.

"Order the following celestial bodies from the biggest to the smallest"

- Sun

- Earth

- Jupiter

- Moon

The correct and incorrect answers of the students to this question are given in Table 9 in frequencies.

Table 9. The distribution of answers for students to close celestial bodies

\begin{tabular}{lc}
\hline Answer & f \\
\hline Correct answer (Sun-Jupiter-Earth-Moon) & 18 \\
\hline Incorrect answer & 12 \\
\hline
\end{tabular}

When the results in Table 9 were examined, it was seen that two third of the students could make the correct order in this question. In addition, when compared with the results in Table 8, the students were found to be more successful in ordering the close celestial bodies than ordering far celestial bodies.

In the last question of the post-test, the students were given a drawing and asked to show where the Sun will rise and set on this drawing.

"In the figure below, where does the Sun rise and set in Samsun on 21" June? Mark.

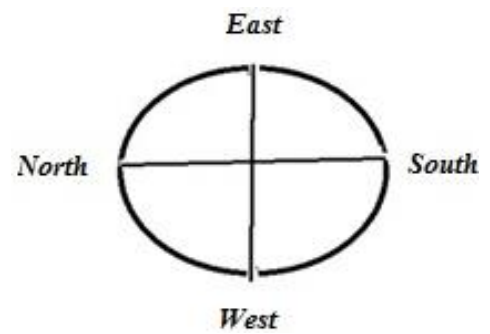

The numbers of correct and incorrect drawings of students in this question were given in frequencies in this question in Table 10 .

Table 10. The number of correct-incorrect drawings of students

\begin{tabular}{lc}
\hline Drawing & f \\
\hline Correct drawing & 21 \\
\hline Incorrect drawing & 9 \\
\hline
\end{tabular}

The results in Table 10 clearly show that the students are more successful in astronomy subjects based on observations that they learn by doing themselves. At the same time, the fact that 21 out of 30 students answered this question correctly shows that the activities of the project were useful.

\section{Conclusion and Discussion}

The purpose of this study was to develop an example model aimed at teaching astronomy to deaf students, to implement this model and to determine the results in students and the limitations in implementation. Every country has different levels of education. We believe that the educational problems of deaf people are higher in Turkey when compared with developed countries. Thus, the data obtained from the students before and after the study were limited. The reason for this may be the poor vocabulary of deaf students in sign language, even the poor vocabulary of these students in their daily lives. Because of this, their writing skills were also found to be quite limited. It was seen that most of the students could not make meaningful sentences. Under these limited conditions, the data were taken from the students only when the model was being implemented and after the model was implemented.

After the model was implemented, the students were asked to write down the new vocabulary they learned about astronomy in sign language with their own hand writing. The fact that a great majority of the students wrote down more 
than 10 new vocabulary shows that the study had a significant success in a short time. In order to teach a subject to deaf students, the sign language about that subject should be developed first (Wang, 2011). Based on the results of this study, we are of the opinion that sign language should be developed with methods and techniques suitable for the subject. The students also have to learn mentally "what the subject is" and "what the subject means". Conceptually, learning and acquiring the sign language should happen simultaneously.

Taking part in scientific studies will contribute to the cognitive, sensory and psychomotor development of deaf students. Within this context, the field of astronomy is one of the most important fields of science in developing cognitive, sensory and psychomotor fields because one of the areas students are most curious about is astronomy (Baxter, 1989; Türk \& Kalkan, 2015a). These observations made in the process of the project on a way to support this idea. Students were observed to be interested to the astronomical event. In addition, it was supported through interviews with students $\mathrm{S}_{7}, \mathrm{~S}_{12}$ and $\mathrm{S}_{20}$ that the activities designed to develop the scientific process skills of students (Table 5) were effective in students. While the students were not able to make any "estimates" and "inferences" in their interviews in $21^{\text {st }}$ June, they began to make "estimates" and "inferences" in their interviews in $23^{\text {rd }}$ September and especially $21^{\text {st }}$ December. In addition, through activities on seasons, the students were able to use many scientific process skills (observing, predicting, communicating, classifying, measuring, collecting recording, and interpreting data, experimentation, making and using models, inferring). Therefore if the activities are organized in a way to increase the students' curiosity and develop their cognitive thinking skills, they will have greater cognitive, sensory and psychomotor development.

The most interesting result that came out of the interviews with deaf students is that the concept of seasons are one of the subjects that the students had most difficulties in commenting and comprehending. Students did not get any education about the seasons during their school life. Thus, the data obtained show their "initial" mental models. In their study with deaf students, Roald \& Mikalsen (2001) found different thoughts about the formation of seasons. These are "the axial tilt of the Earth, the change in the distance of the Earth to the Sun, the shadow of the Moon and the effects of the clouds". In comparison with the results of Roald \& Mikalsen (2001) the students in our study explained the formation of seasons as "the shadow of the Moon" and "the clouds preventing the rays of the Sun". In addition, the alternative thought found in deaf children that "in winter the Sun rays are prevented by dense clouds, thus winter months are colder" support the results obtained from other studies in literature (Baxter, 1989; Dunlop, 2000). In addition, another alternative thought that "the position of the Moon affects the seasons" are in parallel with the results of Sharp's (1996) study.

Another results obtained from seasons was the alternative "the Sun passing just above our heads (from $90^{\circ}$ )" thought. A great number of students believe that the Sun will pass over heads just at midday. This result is not specific only to deaf students, but also other secondary, high school and university students (Türk \& Kalkan, 2015b, Trumper, 2001). With the activities, the students were made to comprehend that the Sun will never pass above our heads and thus, the length of shadow will never be zero.

Another result of the study was that the deaf students could easily recognize and order the celestial bodies. The students were largely able to order the celestial bodies presented to them. Especially, they were able to order the close celestial bodies more easily.

\section{Suggestions}

- It has been thought that it will be useful for the teachers, who will be responsible for teaching astronomy subjects to deaf children; to be educated in education faculties about astronomy subjects will be useful. Thus, Special Education departments should certainly include astronomy lesson. Thus, prospective students will have the necessary equipment before starting their career.

- In addition, it is thought that teachers should be given in-service training to be equipped with information and teaching methods about basic astronomy subjects and increasing the quality of science education to deaf children, cooperating with higher education institutions swill increase the quality of science education.

- In order to be able to assess the results better, control grouped experimental studies can be realized for future studies.

- The efficacy, practibility and limitations of 7 stage model were tried by other researchers and contributed to literature.

- The studies of the researches with deaf students will both contribute to the field and also to the cognitive, sensual and psychomotor development of deaf students. Thus, more studies in this field are recommended at this age.

- It is thought that this model will be a model for the educational studies of deaf students in terms of integrating different media and different methods. 


\section{Acknowledgments}

This work was funded by The Scientific and Technological Research Council of Turkey, Project No: 113 B037.

\section{References}

Barman, C. R., \& Stockton, J. D. (2002). An evaluation of the SOAR-High Project; A web-based science program for deaf students. American Annals of the Deaf, 147(5), 5-10. http://dx.doi.org/10.1353/aad.2012.0211

Baron, N. S. (1981). Speech, writing and sign: A functional view of linguistic representation, Bloomington: Indiana University Press.

Baxter, J. (1989). Children's understanding of familiar astronomical events. International Journal of Science Education, 11, 502-513. http://dx.doi.org/10.1080/0950069890110503

Borrón, R. (1978). Modifying science instruction to meet the needs of the hearing impaired. Journal of Research in Science Teaching, 15, 257-262. http://dx.doi.org/10.1002/tea.3660150404

Boyd, E., \& George, K. (1973). The effect of science inquiry on the abstract categorization behavior of deaf children. Journal of Research in Science Teaching, 10, 91-99. http://dx.doi.org/10.1002/tea.3660100112

Çokluk, Ö., Şekercioğlu, G., \& Büyüköztürk, Ş. (2010). Multivariate statistics for the social sciences: SPSS and LISREL applications. Ankara: Pegem Academy Publishing.

Diebold, T. J., \& Waldron, M. B. (1988). Designing Instructional formats: The effects of verbal and pictorial components on hearing impaired students' comprehension of science concepts. American Annals of the Deaf, 133(5), 30-35. http://dx.doi.org/10.1353/aad.2012.0679

Dunlop, J. (2000). How children observe the universe. Publications of the Astronomical Society of Australia, 17(2), 194-206. http://dx.doi.org/10.1071/AS00194

Egelston-Dodd, J., \& Ting, S. (2007). Video-tutorials for tech sign vocabulary in astronomy. Journal of Science Education for Students with Disabilities, 12(1), 21-26. http://dx.doi.org/10.14448/jsesd.01.0002

Elefant, E. F. (1980). Deaf children in an inquiry training program. Volta Review, 82, 271-279.

GrØnlie, S. M. (1995). Na ${ }^{\circ}$ r noen ikke hører (When someone does not hear) (Bergen: Døves Forlag).

Jones, L. (2014). Developing deaf children's conceptual understanding and scientific argumentation skills: A literature review. Deafness \& education international, 16(3), 146-160. http://dx.doi.org/10.1179/1557069X13Y.0000000032

Lang, H. G., \& Steely, D. (2003). Web-based science instruction for deaf students: What research says to the teacher? Instructional Science, 31(4-5), 277-298. http://dx.doi.org/10.1023/A:1024681909409

Lang, H., \& Albertini, J. (2001). Construction of meaning in the authentic science writing of deaf students. Journal of Studies and Deaf Education, 6, 258-284. http://dx.doi.org/10.1093/deafed/6.4.258

Martin, D. S. (ed.) (1985). Cognition, education and deafness: directions for research and instruction. Washington, DC: Gallaudet University Press.

Mertens, D. M. (1991). Instructional factors related to hearing impaired adolescents' interest in science. Science Education, 75, 429-442. http://dx.doi.org/10.1002/sce.3730750405

Molander, B. O., Pedersen, S., \& Norell, K. (2001). Deaf pupils' reasoning about scientific phenomena: School science as a framework for understanding or as fragments of factual knowledge. Journal of Deaf Studies and Deaf Education, 6, 200-211. http://dx.doi.org/10.1093/deafed/6.3.200

Moores, D. F. (1987). Educating the deaf: Psychology, principles, and practices ( $3^{\text {rd }}$ ed.). Boston: Houghton Mifflin.

Özsoy, Y., Özyürek, M., \& Eripek, S. (1997). Introduction to special education. Ankara: Karatepe Publishings.

Pandian, M. (2006). Cooperative learning incorporating computer-mediated communication: Participation, perceptions, and learning outcomes in a deaf education classroom.

Proust, D., Abbou, D., \& Chab, N. (2009). A dictionary of astronomy for the French sign language (LSF). Proceedings of the International Astronomical Union, 5, 483-489. http://dx.doi.org/10.1017/S1743921311002717

Roald, I., \& Mikalsel, O. (2001). Configuration and dynamics of the earth- sun-moon system: an investigation into conceptions of deaf and hearing pupils. International Journal of Science Education, 23(4), 423-440. http://dx.doi.org/10.1080/09500690119306

Roald, I., \& Mikalsen, O. (2000). What are the Earth and the heavenly bodies like? A study of objectual conceptions among Norwegian deaf and hearing pupils. International Journal of Science Education, 22(4), 337-355. 
http://dx.doi.org/10.1080/095006900289787

Sharp, J. (1996). Children's astronomical beliefs: a preliminary study of year 6 children in south-west England. International Journal of Science Education, 18, 685-712. http://dx.doi.org/10.1080/0950069960180604

Snyder, R. L., Rebscher, S. J., Cao, K., Leake P. A., \& Kelly, K. (1990). Effects of chronicintracochlear electrical stimulation in the neonatally deafened cat. I: Expansion of central spatial representation. Hear Resources, 50, 7-33. http://dx.doi.org/10.1016/0378-5955(90)90030-S

Tanrıöğen, A. (2009). Scientific research methods. Ankara: Anı Publishing.

Trumper, R. (2001). A cross-age study of junior high school students' conceptions of basic astronomy concepts. International Journal of Science Education, 23(11), 1111-1123. http://dx.doi.org/10.1080/09500690010025085

Türk, C., \& Kalkan, H. (2015b). The effect of planetariums on teaching specific astronomy concepts. Journal of Science Education and Technology, 24 (1), 1-15. http://dx.doi.org/10.1007/s10956-014-9516-6

Türk, C., \& Kalkan, H. (2015a). Astronomy attitude scale: Development, validity and reliability, Journal of Studies in Education, 5(4), 23-50.

Vosganoff, D., Paatsch, L. E., \& Toe, D. M. (2011). The Mathematical and science skills of students who are deaf or hard of hearing educated in inclusive settings. Deafness \& Education International, 13(2), 70-88. http://dx.doi.org/10.1179/1557069X11Y.0000000004

Wang, Y. (2011). Inquiry-based science instruction and performance literacy for students who are deaf or hard of hearing. American Annals of the Deaf, 156(3), 239-254. http://dx.doi.org/10.1353/aad.2011.0031

Zamfirov, M., Saeva, S., \& Popov, T. (2007). Innovation in teaching deaf students physics and astronomy in Bulgaria. Physics Education, 42(1), 98-104. http://dx.doi.org/10.1088/0031-9120/42/1/014

This work is licensed under a Creative Commons Attribution 3.0 License. 